\title{
Designing contests between heterogeneous contestants: An experimental study of tie-breaks and bid-caps in all-pay auctions
}

by Aniol Llorente-Saguer, Roman M. Sheremeta and Nora Szech

No. 88 | MAY 2016

\section{WORKING PAPER SERIES IN ECONOMICS}

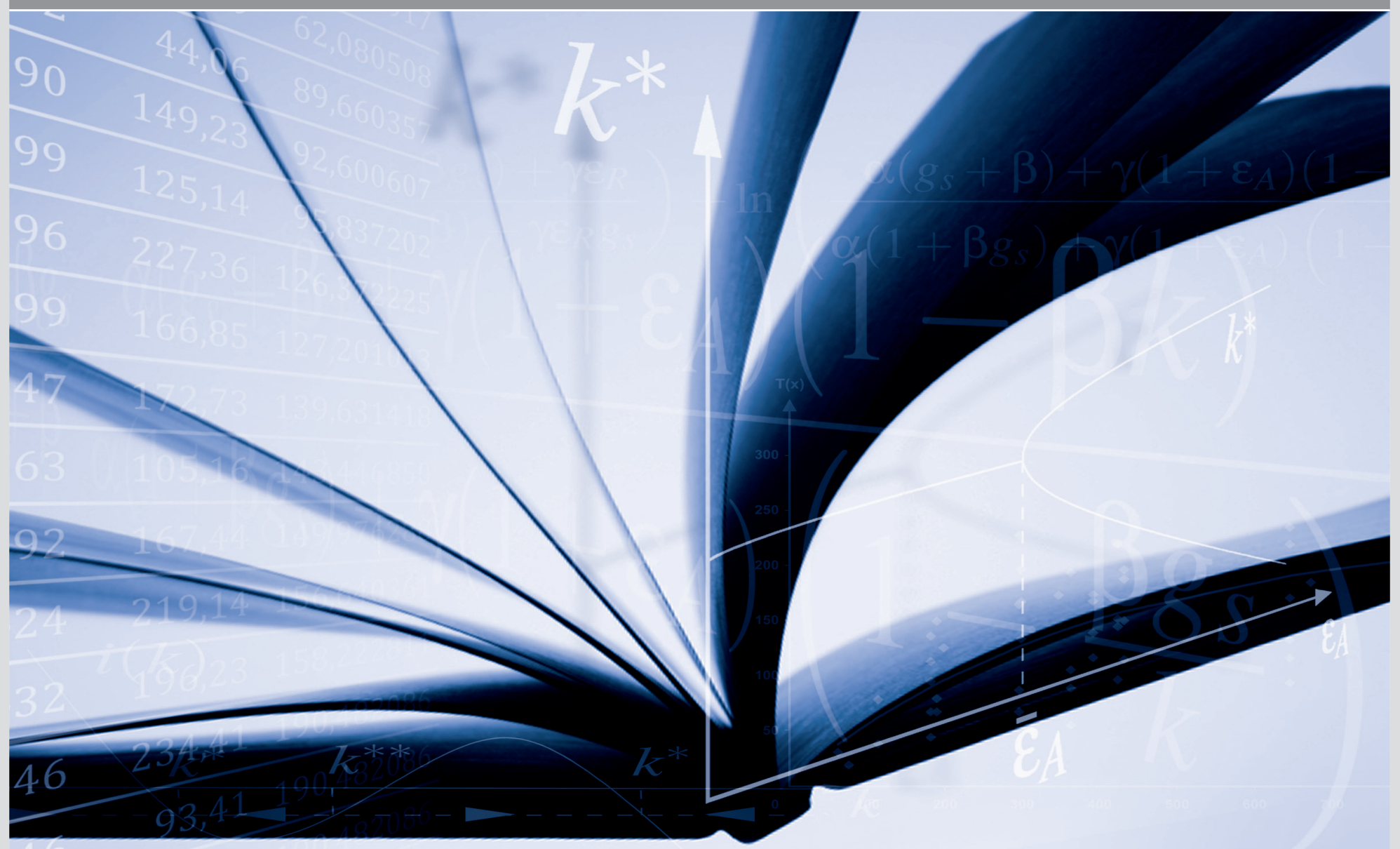




\section{Impressum}

Karlsruher Institut für Technologie (KIT)

Fakultät für Wirtschaftswissenschaften

Institut für Volkswirtschaftslehre (ECON)

Schlossbezirk 12

76131 Karlsruhe

KIT - Die Forschungsuniversität in der Helmholtz-Gemeinschaft

Working Paper Series in Economics

No. 88, May 2016

ISSN 2190-9806

econpapers.wiwi.kit.edu 


\title{
Designing Contests Between Heterogeneous Contestants: An Experimental Study of Tie-Breaks and Bid-Caps in All-Pay Auctions
}

\author{
Aniol Llorente-Saguer ${ }^{\text {a }}$ \\ Roman M. Sheremeta ${ }^{\text {b,c }}$ \\ Nora Szech d,e,f \\ ${ }^{a}$ School of Economics and Finance, Queen Mary University of London, UK \\ ${ }^{\mathrm{b}}$ Weatherhead School of Management, Case Western Reserve University, OH, USA \\ ${ }^{\mathrm{c}}$ Economic Science Institute, Chapman University, CA, USA \\ ${ }^{\mathrm{d}}$ Institute of Economics, Karlsruhe Institute of Technology, Germany \\ ${ }^{\mathrm{e}}$ WZB, Berlin, Germany \\ ${ }^{\mathrm{f}}$ CESifo Institute, Munich, Germany
}

May 8, 2016

\begin{abstract}
A well-known theoretical result in the contest literature is that greater heterogeneity decreases performance of contestants because of the "discouragement effect." Leveling the playing field by favoring weaker contestants through bid-caps and favorable tie-breaking rules can reduce the discouragement effect and increase the designer's revenue. We test these predictions in an experiment. Our data show that indeed, strengthening weaker contestants through tie-breaks and bid-caps significantly diminishes the discouragement effect. Bid-caps can also improve revenue. Most deviations from Nash equilibrium can be explained by the level-k model of reasoning.
\end{abstract}

JEL Classifications: C72, C91, D72

Keywords: all-pay auction, rent-seeking, bid-caps, tie-breaks, contest design

All authors have contributed equally and share first coauthorship. Corresponding authors: Aniol Llorente-Saguer, a.1lorente-saguer@qmul.ac.uk, Roman Sheremeta, rms246@case.edu, and Nora Szech, nora.szech@kit.edu. For helpful comments and suggestions, we want to thank Tim Cason, Andrea Mattozzi, Navin Kartik, Dan Kovenock, Henrik Orzen, Ronald Peeters, Nikolaus Schweizer, and seminar participants at Chapman University, as well as participants at the Contests and Innovation Conference in Anchorage and the North American Economic Science Association Conference in Tucson. Additionally, we thank Frederik Franz, Nicolas Meier and Paul Nobis for research assistance. Sibille Hackel provided excellent administrative support. Any remaining errors are ours. 


\section{Introduction}

Contests are well-established mechanisms for encouraging innovation (Terwiesch and $\mathrm{Xu}$, 2008, Boudreau et al., 2011), incentivizing workers (Lazear and Rosen, 1981), and advancing R\&D (Harris and Vickers, 1985, 1987; Tullock, 1988). A long-standing question within the literature and practice is how to design contests in a way that results in the highest level of performance by contestants (Moldovanu and Sela, 2001; Che and Gale, 2003; for a survey, see Konrad, 2009).

One of the main challenges in contest design is that most contests are held between heterogeneous contestants (Baye et al., 1993; Che and Gale, 1998). A well-known theoretical result in the contest literature is that greater heterogeneity decreases performance of contestants (Konrad, 2009). The reason for this is the so-called "discouragement effect": weaker contestants, either with higher marginal costs or a lower value of winning, cut back expenditures when facing a stronger contestant. Such a discouragement effect has been shown to hold in the field (Brown, 2011), and it is supported by a large body of experimental research (Dechenaux et al., 2015). ${ }^{1}$

One solution suggested by theoretical analysis is to level the playing field by imposing rigid caps on expenditures (Che and Gale, 1998; Gavious et al., 2002, Hart, 2016). Via such bidcaps, weaker contestants are encouraged to compete more intensively, which also increases overall competition. Szech (2015) extends this analysis by showing that a combination of tiebreaking rules favoring the disadvantaged contestant together with appropriately chosen, less rigid bid-caps can foster competition even more. ${ }^{2}$ Both of these policies aim to reduce

\footnotetext{
${ }^{1}$ Experimental studies found support for the discouragement effect in all-pay auctions (Davis and Reilly, 1998; Deck and Sheremeta, 2012; Fehr and Schmidt, 2015), lottery contests (Fonseca, 2009; Kimbrough et al., 2014), rank-order tournaments (Weigelt et al., 1989; Schotter and Weigelt, 1992), and real-effort tournaments (Cason et al., 2010; Gill and Prowse, 2012).

${ }^{2}$ Kaplan and Wettstein (2006) argue that if caps are not rigid, the existence of a cap will not result in increased spending. Cotton (2009) shows that under certain circumstances, a tax on spending is strictly preferred to a spending limit. Fang (2002) demonstrates that the cap paradox of Che and Gale (1998) does not apply to lottery contests.
} 
heterogeneity among contestants, encourage weaker contestants, and strengthen overall competition. This also translates into higher revenue for the designer of the contest.

Despite a well-established theoretical literature, little empirical research has been done to evaluate how bid-caps and tie-breaking rules impact individual behavior and revenue in contests between heterogeneous contestants. To address this gap, we conduct an experiment in which heterogeneous contestants compete in an all-pay auction. Our data confirm that when there is no bid-cap and the tie-breaking rule is symmetric, there is a significant discouragement effect that causes the weaker contestant to bid less than the stronger contestant. Also in line with theory, strengthening the weaker contestant using bid-caps or favorable tie-breaking rules diminishes this discouragement effect and increases the average bid of the weaker contestant. Compared to the unrestricted baseline auction, our data show that the average bid of the weaker contestant is more than $70 \%$ higher when the cap suggested by Che and Gale (1998) is in place. The theoretical analysis in Szech (2015) suggests that a less rigid cap combined with a favorable tiebreaking rule can motivate the weaker contestant even more. Indeed, our data reveal that under such policy, the average bid of the weaker contestant increases by more than $170 \%$ as compared to the unrestricted auction. Furthermore, imposing a sufficiently rigid bid-cap or sufficiently unfavorable tie-breaking rule may decrease the average bid of the stronger contestant. Thus, we find that by setting an appropriate combination of bid-cap and tie-breaking rule, the discouragement effect can be greatly diminished.

Theory predicts that enforcing a rigid bid-cap, as in Che and Gale (1998), should raise the designer's revenue compared to his revenue in an unrestricted all-pay auction. This increase can be even higher if a less rigid cap is combined with a favorable tie-breaking rule, as in Szech

Finally, Szech (2015) shows that the cap paradox vanishes when ties are always broken in favor of the stronger contestant. 
(2015). Our data show that in contrast to the theoretical predictions, the rigid bid-cap does not increase the designer's revenue; yet the less rigid bid-cap increases the designer's revenue. This result holds even when the tie-breaking rule is symmetric. Therefore, while our data cannot confirm the exact theoretical predictions, the basic idea of strengthening competition via appropriately chosen bid-caps is well supported in our experimental findings. By imposing a moderate bid-cap, the contest designer can increase revenue by almost $30 \%$ compared to the unrestricted all-pay auction. Our data also show that, while tie-breaking rules have the power to encourage the weaker contestant, they seem to have no significant overall impact on the designer's revenue in our treatments: A more favorable tie-breaking rule can increase the average bid of the weaker contestant, yet it decreases the average bid of the stronger contestant as well, causing the total revenue to remain unchanged. Most deviations from the Nash equilibrium predictions can be explained by the level-k model of reasoning.

There is a growing experimental literature examining behavior in all-pay auctions; for an overview, see Dechenaux et al. (2015). The studies most closely related to ours are performed by Rapoport and Amaldoss (2000, 2004), Amaldoss and Jain (2002), and Otsubo (2013). ${ }^{3}$ All of these studies examine behavior in all-pay auctions with "coarse" strategy space and a budget constraint (a form of a bid-cap). However, none of the studies treat a bid-cap as a design tool for eliminating the discouragement effect and increasing the revenue. Moreover, with a coarse strategy, pronounced probabilities for ties at various bid levels may arise, making it difficult to examine the interaction between bid-caps and tie-breaks. Finally, all-pay auctions with a discrete strategy space have asymmetric equilibria (Dechenaux et al., 2006; Otsubo, 2015), complicating the interpretation of the actual behavior of participants. Our paper attenuates this issue by having

\footnotetext{
${ }^{3}$ Two other studies by Cohen et al. (2012) and Gelder et al. (2015) investigate the impact of a tie-breaking rule on behavior of symmetric contestants. In both studies, a tie represents a "status quo" and unless one contest outperforms the other by some critical threshold, the status quo does not change.
} 
a fine grid rather than a coarse bidding space. There are other details of our study that make it different from the existing studies, but most importantly, our study is the first to examine how bid-caps and tie-breaks impact individual behavior and revenue in contests between heterogeneous contestants.

We review the theoretical findings on all-pay auctions with bid-caps and tie-breaks in Section 2. The experimental design and procedures are described in Section 3. Our main results are presented in Section 4, along with sub-sections focusing on different parts of the data. We discuss implications of our results in Section 5.

\section{Theory}

Consider an all-pay auction with two risk-neutral contestants. Contestant $H$ values the prize at $v_{H}$ and contestant $L$ at $v_{L}$, where $v_{H}>v_{L}$. Contestants simultaneously submit their bids $b_{H}$ and $b_{L}$, which are capped at $m$. The prize is awarded to the highest bidder, but both contestants need to pay their bids. In the case of a tie, the tie-breaking rule $\alpha$, where $0 \leq \alpha \leq 1$, assigns the prize to contestant $H$ with probability $\alpha$ and to contestant $L$ with probability $1-\alpha$. The revenue of the designer is $R=b_{H}+b_{L}$. If $m>v_{L}$, equilibrium behavior is as in a standard all-pay auction without a cap (Baye et al., 1996). In the mixed strategy Nash equilibrium, the two contestants submit bids according to cumulative distribution functions $F_{H}(b)=b / v_{L}$ and $F_{\mathrm{L}}(b)=1-v_{L} / v_{H}+$ $b / v_{H}$ on an interval $\left[0, v_{L}\right]$. Therefore, the stronger contestant $H$, who has higher valuation for winning, randomly chooses a bid from the interval $\left[0, v_{L}\right]$. The weaker contestant $L$, who has lower valuation for winning, chooses to bid 0 with probability $1-v_{L} / v_{H}$ (because of the discouragement effect), and with the remaining probability randomly chooses a bid from the interval $\left[0, v_{L}\right]$. The expected equilibrium bids of contestants $H$ and $L$ are $E\left(b_{H}\right)=v_{L} / 2$ and $E\left(b_{L}\right)$ 
$=v_{L}^{2} / 2 v_{H}$. This results in an expected total revenue of $R=\left(v_{H}+v_{L}\right) v_{L} / 2 v_{H}$ for the designer. The weaker contestant $L$ earns an expected profit of 0 , while the stronger contestant $H$ earns the difference between the valuations $v_{H}-v_{L}$ (in expected terms).

Che and Gale (1998) show in their game-theoretic analysis that competition can be enhanced by using a rather rigid bid-cap. They focus on the case of symmetric tie-breaking (i.e., the probability that the stronger contestant wins the tie is $\alpha=1 / 2$ ). Through the use of rigid bidcaps, the weaker contestant can be encouraged to bid at the cap in equilibrium. Che and Gale (1998) show that if $m<v_{L} / 2$, the equilibrium bid of both contestants is the bid cap $m$, and thus the total revenue for the designer is $2 m$. Within this class, the revenue is maximized for $m^{*}=$ $v_{L} / 2{ }^{4}$ This leads to a total revenue of $R^{*}=2 m^{*}=v_{L}$ for the designer, which is an improvement over the revenue $R=\left(v_{H}+v_{L}\right) v_{L} / 2 v_{H}$ from the unrestricted auction of Baye et al. (1996). ${ }^{5}$

The basic idea of strengthening competition by leveling the playing field is further elaborated in Szech (2015), who shows that combining a moderate bid-cap with an asymmetric tie-breaking rule in favor of the weaker contestant can further increase competition and revenue. The revenue-maximizing combination is the bid-cap $m^{* *}=\left(1-\alpha^{* *}\right) v_{L}$ and the tie-breaking rule $\alpha^{* *}=v_{L} /\left(v_{H}+v_{L}\right)$. In equilibrium, both contestants bid $m^{* *}$, and both earn zero in expectation. The total revenue for the designer is $R^{* *}=2 m^{* *}=2 v_{H} v_{L} /\left(v_{H}+v_{L}\right)$, which is a further improvement over the revenue $R^{*}=2 m^{*}=v_{L}$ from the capped auction of Che and Gale (1998).

There are several behavioral reasons why these theoretical results may not hold in practice. For example, most all-pay auction experiments find significant overbidding relative to the theoretical predictions (Dechenaux et al., 2015), which could be driven by non-monetary incentives to win the auction (Sheremeta, 2010, 2015) or spite (Hehenkamp et al., 2004; Mago et

\footnotetext{
${ }_{5}^{4}$ At $m^{*}=v_{L} / 2$ there is a multiplicity of equilibria, which can be eliminated by reducing the cap by a small $\varepsilon$.

${ }^{5}$ The cap suggested by Che and Gale (1998) reduces the probability of winning for the high-valuation contestant. Therefore, although $\mathrm{m}^{*}$ increases the organizer's revenue, it reduces the efficiency of the all-pay auction.
} 
al., 2016). Additionally, it is well documented that subjects make mistakes (Camerer, 2003). This could prevent them from using correct best-responses. There is substential evidence that subjects use level-k reasoning when choosing their strategies in auctions (Crawford and Iriberri, 2007; Crawford et al., 2013). Finally, the theoretical predictions of Che and Gale (1998) and Szech (2015) are derived under the assumption of risk neutrality. However, it is well documented that the majority of individuals are risk averse (Holt and Laury, 2002) and that risk preferences can impact behavior in contests (Sheremeta and Zhang, 2010; Mago et al., 2013; Shupp et al., 2013).

\section{Experimental Design and Procedures}

\subsection{Experimental Design}

To study the effects of bid-caps and tie-breaks on behavior in all-pay auctions, we employ five treatments as shown in Table 1. In all treatments, two contestants compete against each other. The stronger contestant's valuation for winning, $v_{H}$, is 180 Talers, and the weaker contestant's valuation for winning, $v_{L}$, is 60 Talers. The treatments differ along two dimensions: the cap $m$ and the tie-breaking rule $\alpha$. We denote treatments using the notation $m_{-} \alpha$.

Treatment 200_1/2 is our baseline treatment. Given the valuations of the contestants, the cap of 200 should not be binding, as in the Nash equilibrium contestants should bid up to 60 , following mixed strategies. Theoretically, tie breaking should be of low importance in this treatment, as ties should practically never occur. For this treatment, we chose the symmetric tiebreaking rule of $\alpha=1 / 2$. According to the theoretical predictions, the revenue in treatment $200 \_1 / 2$ should be 40 , with the stronger contestant bidding 30 and the weaker contestant bidding 10 in expectation. 
Treatment 29_1/2 approximates the policy suggested by Che and Gale (1998). Contestants are restricted to bid up to $m^{*}=29(\varepsilon=1$ is chosen to avoid a multiplicity of equilibria), and tie-breaking is symmetric, i.e., $\alpha=1 / 2$. According to the Nash equilibrium prediction, the designer's revenue in this treatment should increase to 58, with both contestants bidding the cap of 29 .

Szech (2015) suggests combining a tie-breaking rule in favor of the weaker contestant with a less rigid bid-cap in order to further encourage the weaker contestant and also increase the designer's revenue. To approximate the globally optimal combination of a bid-cap $m^{* *}$ and tiebreaking rule $\alpha^{* *}$, we implement treatment 53_1/6. In the case of a tie, the stronger contestant wins with a probability of $\alpha^{* *}=1 / 6$ while the weaker contestant wins with a probability of $5 / 6 .^{6}$ Theoretically, treatment $53 \_1 / 6$ should lead to the expected revenue of 80 , with an expected bid of 47 by the weaker contestant and 33.3 by the stronger contestant.

It may be difficult for participants to understand a tie-breaking rule that works differently from simple winning probabilities such as $0,1 / 2$ (i.e., the toss of a fair coin), or 1 . A way to eliminate this problem is to loosely approximate the theoretically optimal solution with a tiebreaking rule that is easy to understand. As a simplification of treatment $53 \_1 / 6$, we also run treatment 53_0, in which the tie-breaking rule $\alpha=0$ is always in favor of the weaker contestant. Theoretically, treatment $53 \_0$ should lead to the revenue of 68 , an expected bid of 45.2 by the weaker contestant and 23.4 by the stronger contestant.

To complete our understanding of the impact of tie-breaks, we also run treatment 53_1/2 with a symmetric tie-breaking rule of $\alpha=1 / 2$. This treatment facilitates comparisons with treatments $53 \_1 / 6$ and $53 \_0$ as well as with treatment $29 \_1 / 2$. Theoretically, treatment $53 \_1 / 2$

\footnotetext{
${ }^{6}$ Using the winning probability of $1 / 6$ has the advantage that participants may recall this probability from playing cardboard games involving dice throws.
} 
should generate a revenue of 40 . The stronger contestant is expected to bid 30 , and the weaker contestant is expected to bid 10 .

\subsection{Experimental Procedures}

We conducted the experiment at the University of Bonn. 240 participants were recruited via ORSEE (Greiner, 2015) from the participant pool consisting mainly of undergraduate students. There was a total of 10 experimental sessions ( 2 per treatment) with 24 participants in each session (between-subject design). Participants interacted via visually isolated computer terminals, and the experiment was programmed and conducted with the experiment software zTree (Fischbacher, 2007). At the beginning of the experiment, each participant received a copy of the instructions (available in the Appendix), which an experimenter read out loud. Participants were informed about their initial endowment of 15 Euros (which we describe as a participation fee). They were also introduced to the in-game currency "Talers" and informed about the conversion rate of 60 Talers to 1 Euro.

Each session consisted of 40 periods of an all-pay auction. The design of the auction was kept identical across all 40 periods. In the first period, participants were assigned to the specific role of either contestant $H$ (framed as player 1) or contestant $L$ (framed as player 2). Participants remained in their roles for the first 20 periods of the experiment. For the last 20 periods, participants switched their roles, so all contestants $H$ became contestants $L$ and vice versa. ${ }^{7}$ Each period, participants were randomly rematched with participants of the opposite type. In each session, random matching occurred within three different subgroups. Hence, we obtained three independent observations per session.

\footnotetext{
${ }^{7}$ The process of role switching after period 20 was used to mitigate any concerns about fairness and inequality among participants in the experiment.
} 
In the baseline treatment, participants could bid any amount between 0 and 200 Talers, up to one decimal point. In the other treatments, participants could bid any amount between 0 and the bid-cap, up to one decimal point. At the end of each period, the computer displayed individual bids as well as individual payoffs. To reinforce the one-shot incentives of the game, 4 of the 40 periods were selected for payment. Participants' total earnings from these 4 periods were added to their initial endowment of 15 Euros. $^{8}$ At the end of the experiment, participants answered a series of demographic and socioeconomic questions. The experimental sessions lasted about 90 minutes each.

\section{Results}

In the following analysis, we focus on the data from all 40 periods. Furthermore, in order to account for differential dynamics across treatments, we indicate whether the results are robust to considering only the second half of each part (periods 11-20 and 31-40). When performing the non-parametric tests, we use the average within a single rematching group of eight participants over all periods of the experiment as one independent observation (six independent observations per treatment). When performing regression analysis, we control for individual participant effects and correlation within a matching group.

\subsection{Bids by Type}

\subsubsection{Behavior of the Weaker Contestant}

Table 2 displays average bids, payoffs, and revenue by treatment. The top part of the table presents the data for all 40 periods. The bottom part presents the data from periods 11-20

\footnotetext{
${ }^{8}$ If the total payoff of the 4 selected periods was negative, the absolute value of this amount was subtracted from the initial endowment.
} 
and $31-40$ as a robustness check. We begin by focusing on the discouragement effect. According to theory, the weaker contestant $L$ should experience a discouragement effect in treatment $200 \_1 / 2$ compared to the stronger contestant. Indeed, we see that the weaker contestant bids three times less than the stronger contestant (11.7 versus 35.2; Wilcoxon rank-sum test, p-value $<0.01)^{9}$

Theory predicts that strengthening the weaker contestant $L$ should enhance competition and increase $L$ 's average bid. One way of strengthening the weaker contestant is by placing a bid-cap on both contestants while keeping the tie-breaking rule symmetric. Such leveling of the playing field should encourage the weaker contestant to increase his average bid (Che and Gale, 1998). In line with this prediction, treatment $29 \_1 / 2$ significantly increases the average bid by the weaker contestant compared to the baseline treatment 200_1/2 (20.2 versus 11.7; Wilcoxon ranksum test, p-value $<0.01$ ), indicating that the cap of $m=29$ significantly diminishes the discouragement effect. ${ }^{10}$

Theory predicts that less rigid bid-caps combined with tie-breaking rules in favor of the weaker contestant have the potential to reduce the discouragement effect even more. This is what we find. Tie-breaking completely in favor of the weaker contestant encourages him: In treatment 53_0, the weaker contestant competes more than in treatment 53_1/2 (32.3 versus 20.5; Wilcoxon rank-sum test, $\mathrm{p}$-value $=0.01$ ). Theory also predicts a comparable effect via a tiebreaking that is often but not always in favor of the weaker contestant, as in treatment 53_1/6. Theoretically, competition should be high here, as the stronger contestant has now a (slim) chance of winning in the event of a tie. Indeed, in our data, encouragement of the weaker

\footnotetext{
${ }^{9}$ This result also holds when examining the data from the second half of each part of the experiment (12.4 versus 33.3; Wilcoxon rank-sum test, p-value $<0.01$ ).

${ }^{10}$ This result is robust when examining the data from the second half of each part of the experiment (12.4 versus 20.2; Wilcoxon rank-sum test, $\mathrm{p}$-value $=0.01$ )
} 
contestant remains high despite high competition from the stronger contestant (27.9 versus 32.3; Wilcoxon rank-sum test, $\mathrm{p}$-value $=0.20)$. Treatment 53 _1/6 also remains a significant improvement over treatment 53_1/2 with the symmetric tie-breaking rule (27.9 versus 20.5 ; Wilcoxon rank-sum test, $\mathrm{p}$-value $=0.03$ ). These results hold when examining the second half of bidding rounds, indicating that tie-breaking rules play an important role in further reducing the discouragement effect.

Even the symmetric treatment 53_1/2 outperforms the unrestricted treatment $200 \_1 / 2$ (20.5 versus 11.7 ; Wilcoxon rank-sum test, $\mathrm{p}$-value $=0.01) .{ }^{11}$ This result is in contrast to theory. In our data, encouragement in treatment $53 \_1 / 2$ and treatment $29 \_1 / 2$ is very similar when examining all periods of the experiment (20.5 versus 20.2 ; Wilcoxon rank-sum test, $\mathrm{p}$-value $=$ $0.87)$ and when examining only the second half (20.2 versus 17.5 ; Wilcoxon rank-sum test, pvalue $=0.33$ ). This suggests that even with a symmetric tie-breaking rule, the less rigid bid-cap is a good method of encouraging the weaker contestant.

To further check the robustness of our non-parametric tests, we estimate a random effects GLS regression of the bid on dummies indicating the interaction between a treatment and a bidder type (with bids of low types in the $200 \_1 / 2$ treatment as the reference group) and a constant. ${ }^{12}$ The estimation results are reported in Table 3 . Based on these estimation results, we provide pairwise comparisons of the weaker contestant's bids across treatments, reported in Table 4. Consistent with the non-parametric tests, the introduction of a rigid bid-cap motivates

\footnotetext{
${ }^{11}$ This difference becomes not significant if we restrict the analysis to the second half of each part (Wilcoxon ranksum test, $\mathrm{p}$-value $=0.15$ ).

${ }^{12} \mathrm{We}$ ran this regression to ease the interpretation of the coefficients. Adding controls for the number of periods and the number of the part played, did not change any of the results presented. In order to account for differential learning across treatments, we indicate robustness of the results when considering only the later bidding rounds in the respective roles, i.e., rounds 11 to 20 and 31 to 40 .
} 
the weaker contestant, and a less rigid bid-cap combined with a favorable tie-breaking rule leads to the strongest encouragement.

It is important to emphasize that the effects of bid-caps and tie-breaks are not only statistically significant but also economically meaningful. Compared to the unrestricted baseline auction, the average bid of the weaker contestant is more than $70 \%$ higher when the cap suggested by Che and Gale (1998) is in place together with a symmetric tie-breaking. A less rigid cap combined with a favorable tie-breaking rule can increase the average bid of the weaker contestant by more than $170 \%$ as compared to the unrestricted auction. Thus, by setting an appropriate bid-cap and a favorable tie-breaking rule, the discouragement effect can be greatly diminished.

Result 1. Strengthening the weaker contestant by placing a rigid or a less rigid bid-cap both significantly reduces the discouragement effect. A less rigid bid-cap combined with a favorable tie-breaking rule further increases the average bid of the weaker contestant.

\subsubsection{Behavior of the Stronger Contestant}

We now turn to the bidding behavior of the stronger contestant. In line with the Nash equilibrium prediction, we find no significant difference in average bidding behavior between treatments 53_1/2 and 200_1/2 (38.6 versus 35.2; Wilcoxon rank-sum test, p-value $=0.14)$. Yet in both treatments, bids tend to be a bit higher than the theoretically predicted 30.0 (see Table 1). Theoretical analysis further predicts a slight decrease when the cap is $m=29$ : The contestant should bid at the cap. Our data reveal a more substantial and significant decrease (to an average bid of 25.3). The average bid of the stronger contestant in treatment 29_1/2 is significantly lower than in treatments $53 \_1 / 2$ and $200 \_1 / 2$ (both p-values $<0.01$ ). These results are robust to 
focusing on the respective second half of bidding rounds, indicating that a sufficiently rigid bidcap decreases the average bid of the stronger contestant.

The data further reveal that the stronger contestant responds systematically to changes in the tie-breaking rule. Specifically, holding the bid-cap at $m=53$, the average bid of the stronger contestant is highest when the tie-breaking rule is $\alpha=1 / 2$. When the tie-breaking rule is in favor of the weaker contestant (i.e., $\alpha=1 / 6$ and $\alpha=0$ ), the average bid of the stronger contestant decreases. Both treatments $53 \_1 / 6$ and $53 \_0$ are significantly different from treatment $53 \_1 / 2$ at the 0.01 significance level. Theoretically, this discouragement should only be observed for the 53_0 treatment. In the data, there is no significant difference in bidding behavior between treatment 53_1/6 and treatment 53_0 (29.3 versus 27.0; Wilcoxon rank-sum test, $\mathrm{p}$-value $=0.26)$. These results are robust to only considering the data from the second half of bidding rounds.

To further check the robustness of our non-parametric tests, we provide pairwise comparisons of the stronger contestant's bids across treatments in Table 5. These comparisons are based on the estimation results presented in Table 3. Consistent with the non-parametric tests, the stronger contestant bids less when there is a rigid bid-cap, and reacts to an unfavorable tiebreaking rule compared to a symmetric one.

Result 2. Imposing a rigid bid-cap, or a less rigid bid-cap combined with an unfavorable tie-breaking rule, decreases the average bid of the stronger contestant.

\subsection{Revenue}

This section presents a ranking of the treatments with regard to revenue generated. In other words, we want to know how different combinations of the bid-cap and tie-breaking rule affect total revenue. Revenue equals the sum of bids exerted by the stronger and weaker 
contestants. According to Results 1 and 2, a sufficiently rigid bid-cap increases the bid of the weaker contestant and decreases the bid of the stronger contestant. Therefore, the total effect of a bid-cap on the revenue is ambiguous. The theoretical prediction of Che and Gale (1998) is that placing a bid-cap of $m=29$ under symmetric tie-breaking should raise the revenue relatively to an unrestricted all-pay auction. Our data show that, in contrast to this prediction, revenue in treatment $29 \_1 / 2$ is not signficantly different than revenue in the baseline treatment $200 \_1 / 2$ (45.5 versus 46.9; Wilcoxon rank-sum test, $\mathrm{p}$-value $=0.87$ ). The reason for this departure is twofold. On the one hand, revenue in treatment $200 \_1 / 2$ is significantly higher than predicted (46.9 versus 40.0; Wilcoxon signed-rank test, $p$-value $=0.02$ ). Such overbidding is common in all-pay auction experiments (Davis and Reilly, 1998; Gneezy and Smorodinsky, 2006; Lugovskyy et al., 2010; Chen et al., 2015). ${ }^{13}$ On the other hand, revenue in treatment $29 \_1 / 2$ is significantly lower than predicted (45.5 versus 58.0; Wilcoxon signed-rank test, p-value $=0.02$ ) For this treatment, the Nash equilibrium is at the upper boundary of the bidding space (i.e., both bidders should bid at the cap), so any deviation from equilibrium implies a lower-than-predicted revenue. ${ }^{14}$ As a result of these two effects, we find that contrary to the theoretical prediction of Che and Gale (1998), a rigid bid-cap of $m=29$ does not increase the designer's revenue. ${ }^{15}$

Theory also predicts that among all combinations of caps and tie-breaks, using a less rigid bid-cap combined with a tie-breaking rule favoring the weaker contestant is the most effective way of increasing revenue in all-pay auctions with heterogeneous contestants (Szech, 2015). Indeed, we find that treatment 53_0 generates significantly higher revenue than treatments

\footnotetext{
13 A number of explanations for overbidding have been offered, including bounded rationality (Sheremeta, 2011; Chowdhury et al., 2014; Lim et al., 2014), the utility of winning (Sheremeta, 2010; Cason et al., 2012, 2015), relative payoff maximization (Sheremeta, 2013, 2015; Mago et al., 2016), and limited cognitive ability (Sheremeta, 2016).

14 This problem of equilibrium predictions at the boundary has been well recognized in linear public good experiments, where the dominant strategy is to contribute nothing. For a review, see Laury and Holt (2008).

${ }^{15}$ This conclusion stands when one examines the data from the second half of our experiment.
} 
200_1/2 and 29_1/2. This holds across the data from all periods (Wilcoxon rank-sum test, pvalues $=0.01$ and 0.01 ) and is robust to focusing on the second half of bidding rounds (Wilcoxon rank-sum test, $\mathrm{p}$-values $=0.01$ and 0.01 ). Another theoretical prediction is that under the less rigid bid-cap of $m=53$, the revenue in treatment 53_1/6 should be the highest, followed by 53_0, and then by 53_1/2. Our data, however, does not display significant differences between these three treatments (Wilcoxon rank-sum test, p-values $=0.42,0.74$, and 0.63 ). ${ }^{16}$ The reason behind this is as follows: A more favorable tie-breaking rule increases the average bid of the weaker contestant, yet it also decreases the average bid of the stronger contestant, causing the total revenue to remain unchanged. Nonetheless, all three treatments $-53 \_1 / 6,53 \_0$, and $53 \_1 / 2$ - generate significantly higher revenues than the unrestricted baseline treatment 200_1/2 (Wilcoxon rank-sum test, p-values $=0.03,0.01$, and 0.05$)$ and treatment $29 \_1 / 2($ Wilcoxon ranksum test, $\mathrm{p}$-values $=0.01,0.01$, and 0.01$) \cdot{ }^{17}$ Revenue increases substantially, amounting to almost $30 \%$ higher than that of the unrestricted all-pay auction.

To further check the robustness of our non-parametric tests, we provide pairwise comparisons of the revenue across treatments in Table 6. These comparisons are based on the estimation results presented in Table 3. Consistent with the non-parametric tests, we find that a less rigid bid-cap increases the designer's revenue, independent of the tie-breaking rule.

Result 3. Imposing a less rigid bid-cap increases the designer's revenue, regardless of the tie-breaking rule.

\footnotetext{
${ }^{16}$ The comparison between $53 \_1 / 6$ and $53 \_1 / 2$ becomes marginally significant when we only consider the second half of each part (Wilcoxon rank-sum test, $\mathrm{p}$-value $=0.08$ ).

${ }^{17}$ When we restrict our analysis to the second half of each part, the results remain significant only when comparing treatment $53 \_0$ to $200 \_1 / 2$ and treatment $53 \_0$ to $29 \_1 / 2$.
} 


\subsection{Distribution of Bids}

Despite the fact that most theoretical predictions are supported by our data, there are some departures from the Nash equilibrium. In order to better understand such departures, we examine the distribution of bids across types and treatments. Figure 1 displays the realized and the predictive cumulative distributions of bids for each treatment and type. Overall, we see that the observed data is fairly consistent with the theoretical predictions.

In the unrestricted treatment $200 \_1 / 2$, as predicted by standard theory, most bids by both types are between 0 and 60.0 . Only $2.5 \%$ of bids are strictly above 61.0 , and only $1.1 \%$ are strictly above 65.0. In fact, the bidding behavior of the weaker contestant is not significantly different than what theory predicts (11.7 versus 10.0 ; Wilcoxon signed-rank test, $\mathrm{p}$-value $=0.34$ ) The bidding behavior of the stronger contestant, however, is more intense than predicted (35.2 versus 30.0; Wilcoxon signed-rank test, $\mathrm{p}$-value $=0.02$ ). From Figure 1 we can see that this overbidding comes primarily from participants placing a significant mass point around 60 (which is not predicted by standard theory).

In treatment $29 \_1 / 2$, theory predicts that all bids should be concentated at the bid-cap of 29. Indeed, we find that the stronger contestant uses this strategy $82.6 \%$ of the time. Although the average bid is significantly lower than predicted (25.3 versus 29.0; Wilcoxon signed-rank test, $\mathrm{p}$-value $=0.02$ ), the weaker contestant also concentrates his bids around the bid-cap, as theoretically predicted. Yet there is also a mass point around 0 that is not predicted by theory, and it is even more pronounced than that of the stronger contestant (the frequency of bidding zero is significantly higher; Wilcoxon signed-rank test, $\mathrm{p}$-value $=0.03$ ).

The only difference across the three treatments with a bid-cap of 53 is the tie-breaking rule. We see that effects of tie-breaking on bidding behavior are substantial. The weaker 
contestant shifts mass from 0 to the cap as the tie-breaking rule becomes more favorable. At the same time, the stronger contestant displays the reverse bidding behavior by shifting mass from the cap to 0 as the tie-breaking rule becomes less favorable for him or her. Focusing on treatments $53 \_0$ and $53 \_1 / 2$ in which the tie-breaking rule is relatively easy to understand, the shifts in the mass points are in line with the Nash equilibrium prediction. This is not the case for treatment 53 _1/6. Here, we observe again substantial mass at 0 , which is not predicted by theory. One possible explanation is that participants are more confused when the tie-breaking rule is more complex (i.e., $1 / 6$ versus 0 or $1 / 2$ ). This might be the reason why this treatment does not outperform the other treatments, as theory would predict.

\subsection{Behavioral Explanations Based on Level-k Reasoning}

Our data reveal substantial mass points at some bid levels that are not in line with the standard game-theoretic predictions. A potential explanation for these mass points comes from a level-k model of reasoning (Stahl and Wilson, 1994, 1995; Nagel, 1995). ${ }^{18}$ This model assumes that the population is partitioned into types that differ in their depth of reasoning. A level-0 type is nonstrategic and follows a simple decision rule. The level-1 type behaves as if best-responding to the belief that the other is a level-0 type. Similar logic applies to other types. People typically exhibit level-0, level-1, or level-2 reasoning; it is very uncommon to observe level-4 reasoning or higher (Arad and Rubinstein, 2012; Crawford et al., 2013). ${ }^{19}$

\footnotetext{
${ }^{18}$ Other prominent models of bounded rationality include quantal response equilibrium (McKelvey and Palfrey, 1995) and cursed equilibrium (Eyster and Rabin, 2005). Goeree et al. (2002) show that quantal response equilibrium can indeed account for some of the departures observed in private value first price auctions. In our setup, however, quantal response equilibrium cannot account for the pronounced peaks observed at zero and the cap. Also, since our game is a game of complete information, cursed equilibrium coincides with the Nash prediction.

${ }^{19}$ Level-k reasoning has been used to explain the behavior in auctions (Crawford and Iriberri, 2007), beauty contests (Nagel, 1995), guessing games (Stahl and Wilson, 1994, 1995), coordination games (Crawford et al., 2008), and centipede games (Kawagoe and Takizawa, 2012).
} 
Table 7 displays bidding behaviors according to level-k for the stronger contestant $H$ and the weaker contestant $L$. We assume that a level-0 type randomly chooses a bid between 0 and the bid-cap ( 60 in the baseline treatment). Recall that the main deviation from the theory in the baseline treatment 200_1/2 comes from the stronger contestant placing a mass point around 60 . The prediction from the level-k model is that the stronger contestant behaving as a level-1 type should best respond to the weaker contestant behaving as level- 0 type by bidding 60 . Therefore, the mass point around 60, which is not predicted by standard theory, is perfectly consistent with the level-k reasoning.

In treatment 29_1/2, level-k analysis predicts that level-1 reasoning or higher implies bidding at the cap of 29. The level-0 types should bid randomly between 0 and 29 . Therefore, assuming that there are some level-0 types as well as other types explains our data. Although the small mass point around 0 by the weaker contestants cannot be explained by the level-k reasoning, it can be explained by risk aversion. ${ }^{20}$

In treatments with a cap of 53, the level-k model also seems to provide a good approximation for the behavior of participants. First, the mass points at 0 and 53 observed in the data are well captured by level-1 and level-2 types. Second, the level-k model also captures well the comparative statics with respect to the tie-breaking rule. The bid distribution for the stronger contestant displays mass points of comparable sizes when the tie-breaking rule is $\alpha=0$ and $\alpha=$ $1 / 6$, and a much more pronounced mass point at the cap when the rule is $\alpha=1 / 2$. The bid distributions for the weaker contestant, on the other hand, show a reverse pattern: The frequency of bidding zero increases when the tie-breaking rule becomes less favorable.

\footnotetext{
${ }^{20}$ Looking at our data on self-reported willingness to take risks (where 0 denotes "completely unwilling to take risks" and 10 denotes "completely prepared to take risks"), we find that participants who indicate that they are unwilling to take risks avoid bidding at the cap of 29. A random effects GLS regression of the probability of bidding zero on our risk measure shows a significant relationship (p-value $<0.01$ ).
} 
Result 4. Most deviations from the standard game-theoretic predictions can be explained by the level-k model of reasoning.

\section{Conclusions}

We study how bid-caps and tie-breaks impact individual behavior and revenue in all-pay auctions between heterogeneous contestants. Theory predicts that greater heterogeneity decreases the performance of contestants because of the "discouragement effect." Leveling the playing field by favoring weaker contestants through bid-caps and favorable tie-breaking rules can reduce the discouragement effect and increase the designer's revenue. Our experimental data confirm that placing bid-caps and using favorable tie-breaking rules significantly diminishes the discouragement effect. The impact on the revenue, however, is not as clear. Although an appropriately chosen bid-cap can increase the revenue, the cap should be less rigid than predicted. Our data also show that tie-breaking rules seem to have little impact on the designer's revenue. Most deviations from Nash equilibrium can be explained by the level-k model of reasoning.

It has been well recognized that the discouragement effect can decrease the performance of contestants in the field (Brown, 2011) and in the lab (Dechenaux et al., 2015). One theoretical solution that has been proposed is to impose a rather rigid cap on expenditures (Che and Gale, 1998). Theoretically, even better effects are attainable when implementing a less rigid cap combined with a tie-breaking rule favoring the weaker contestant (Szech, 2015). We provide empirical evidence that these policies are indeed powerful. Compared to the unrestricted baseline auction, our data show that the average bid of the weaker contestant is more than $70 \%$ higher when the rigid cap suggested by Che and Gale (1998) is in place. An appropriate combination of 
a less rigid bid-cap and a favorable tie-breaking rule can further increase the average bid of the weaker contestant, such that he bids more than $170 \%$ higher as compared to the unrestricted contest.

Our study also contributes to a growing literature on innovation contests (Terwiesch and Xu, 2008, Boudreau et al., 2011). It is estimated that the "contest industry" might have a value of up to two billion dollars (McKinsey and Company, 2009). An important objective of a contest designer is usually to increase both the performance of contestants and total revenue. Theoretically, this could be done by using a rather rigid bid-cap as in Che and Gale (1998), and even more so by implementing a less rigid bid-cap combined with an appropriate tie-breaking rule (Szech, 2015). We find that a less rigid cap can indeed be more effective at increasing revenue. Yet tie-breaking, while important for the respective bids by stronger and weaker contestants, seems to play no significant role in affecting the designer's revenue. These empirical findings may explain why in practice, the designers of innovation contests place relatively small restrictions on contestants and often stick to symmetric tie-breaking when focusing on overall revenues (Jeppesen and Lakhani, 2010; Boudreau et al., 2011). In other cases, objectives may include encouraging weaker contestants, as for example in sports competitions (to level the playing field and create more of a thrill for viewers) or labor markets (to increase diversity); here, tie-breaking rules in favor of the weaker contestants may prove very useful. Antidiscrimination policies that solve ties in favor of specific subgroups of a population may benefit from these effects. In sports, asymmetric tie-breaking exists, for instance, in the Champions League soccer playoffs: In the case of a tie, "away goals" become the decisive factor in determining the winning team. 
Finally, our study contributes to a large literature on rent-seeking. Since the seminal papers of Tullock (1967) and Krueger (1974), rent-seeking has inspired a vast literature. The idea of rent-seeking is simple - different economic and political groups are trying to increase their profits and influence through a competitive and sometimes illegal process. Pressure groups, for example, can use lobbying to influence a politician's decision and thus obtain a prize or favor. Politicians, on the other hand, may implicitly or explicitly auction off a prize to the highestbidding lobbyist. The process by which politicians sell favors is often modeled as an all-pay contest (Tullock, 1980; Hillman and Riley, 1989; Baye et al., 1993; Che and Gale, 1998). The amount of rents the politician can earn depends on the amount of rent-seeking expenditures by the lobbyists (contestants in our case). In contrast to innovation contests, however, expenditures are often considered to be socially wasteful. Using a theoretical model, Che and Gale (1998) show that a rigid bid-cap may actually increase aggregate expenditures. However, they caution the reader against generalizing their results without a proper empirical investigation. Our experimental examination shows that such caution is indeed warranted - although the unwanted effects on aggregate spending may emerge only if caps are less rigid. 


\section{References}

Amaldoss, W., \& Jain, S. (2002). David vs. Goliath: An analysis of asymmetric mixed-strategy games and experimental evidence. Management Science, 48, 972-991.

Arad, A., \& Rubinstein, A. (2012). The 11-20 money request game: a level-k reasoning study. American Economic Review, 102, 3561-3573.

Baye, M.R., Kovenock, D., \& de Vries, C.G. (1993). Rigging the lobbying process: An application of the all-pay auction. American Economic Review, 83, 289-294.

Baye, M.R., Kovenock, D., \& de Vries, C.G. (1996). The all-pay auction with complete information. Economic Theory, 8, 291-305.

Boudreau, K.J., Lacetera, N., \& Lakhani, K.R. (2011). Incentives and problem uncertainty in innovation contests: An empirical analysis. Management Science, 57, 843-863.

Brown, J. (2011). Quitters never win: The (adverse) incentive effects of competing with superstars. Journal of Political Economy, 119, 982-1013.

Camerer, C. (2003). Behavioral game theory. Princeton, NJ: Princeton University Press.

Cason, T.N., Masters, W.A., \& Sheremeta, R.M. (2010). Entry into winner-take-all and proportional-prize contests: An experimental study. Journal of Public Economics, 94, 604-611.

Cason, T.N., Sheremeta, R.M. \& Zhang, J. (2012). Communication and efficiency in competitive coordination games. Games and Economic Behavior, 76, 26-43.

Cason, T.N., Sheremeta, R.M. \& Zhang, J. (2015). Asymmetric and endogenous communication in competition between groups. Working Paper.

Che, Y.K., \& Gale, I.L. (1998). Caps on political lobbying. American Economic Review, 88, 643-651.

Che, Y.K., \& Gale, I.L. (2003). Optimal design of research tournaments. American Economic Review, 93, 646-671.

Chen, Z.C., Ong, D., \& Sheremeta, R. M. (2015). The gender difference in the value of winning. Economics Letters, 137, 226-222.

Chowdhury, S.M., Sheremeta, R.M., \& Turocy, T.L. (2014). Overbidding and overspreading in rent-seeking experiments: Cost structure and prize allocation rules. Games and Economic Behavior, 87, 224-238.

Cohen, C., Shavit, T., \& Rosenboim, M. (2012). The over-weighting of unfair tie in all-pay contest: An experimental study. International Journal of Economic Theory, 8, 301-311.

Cotton, C. (2009). Should we tax or cap political contributions? A lobbying model with policy favors and access. Journal of Public Economics, 93, 831-842.

Crawford, V. P., Costa-Gomes, M.A., \& Iriberri, N. (2013). Structural models of nonequilibrium strategic thinking: Theory, evidence, and applications. Journal of Economic Literature, $51,5-62$.

Crawford, V.P., \& Iriberri, N. (2007). Level-k auctions: Can a non-equilibrium model of strategic thinking explain the winner's curse and overbidding in private-value auctions? Econometrica, 75, 1721-1770.

Crawford, V.P., Gneezy, U., \& Rottenstreich, Y. (2008). The power of focal points is limited: Even minute payoff asymmetry may yield large coordination failures. American Economic Review, 98, 1443-1458.

Davis, D., \& Reilly, R. (1998). Do many cooks always spoil the stew? An experimental analysis of rent seeking and the role of a strategic buyer. Public Choice, 95, 89-115. 
Dechenaux, E., Kovenock, D., \& Lugovskyy, V. (2006). Caps on bidding in all-pay auctions: Comments on the experiments of A. Rapoport and W. Amaldoss. Journal of Economic Behavior and Organization, 61, 276-283.

Dechenaux, E., Kovenock, D., \& Sheremeta, R. M. (2015). A survey of experimental research on contests, all-pay auctions and tournaments. Experimental Economics, 18, 609-669.

Deck, C., \& Sheremeta, R.M. (2012). Fight or flight? Defending against sequential attacks in the game of siege. Journal of Conflict Resolution, 56, 1069-1088.

Eyster, E., \& Rabin, M. (2005). Cursed equilibrium. Econometrica, 73, 1623-1672.

Fang, H. (2002). Lottery versus all-pay auction models of lobbying. Public Choice, 112, 351371.

Fehr, D., \& Schmidt, J. (2015). Exclusion in the all-pay auction: An experimental investigation. Working Paper.

Fischbacher, U. (2007). z-Tree: Zurich toolbox for ready-made economic experiments. Experimental Economics, 10, 171-178.

Fonseca, M.A. (2009). An experimental investigation of asymmetric contests. International Journal of Industrial Organization, 27, 582-591.

Gavious, A., Moldovanu, B., \& Sela, A. (2002). Bid costs and endogenous bid caps. RAND Journal of Economics, 33, 709-722.

Gelder, A., Kovenock, D., \& Sheremeta, R. (2015). Behavior in all-pay auctions with ties. Working Paper.

Gill, D., \& Prowse, V. (2012). A structural analysis of disappointment aversion in a real effort competition. American Economic Review, 102, 469-503.

Gneezy, U., \& Smorodinsky, R. (2006). All-pay auctions - an experimental study. Journal of Economic Behavior and Organization, 61, 255-275.

Goeree, J.K, Holt, C.A., \& Palfrey, T.R. (2002). Quantal response equilibrium and overbidding in private-value auctions. Journal of Economic Theory, 104, 247-272.

Greiner, B. (2015). Subject pool recruitment procedures: Organizing experiments with ORSEE. Journal of the Economic Science Association, 1, 114-125.

Harris, C. \& Vickers, J. (1985). Perfect equilibrium in a model of a race. Review of Economic Studies, 52, 193-209.

Harris, C. \& Vickers, J. (1987). Racing with uncertainty. Review of Economic Studies, 54, 1-21.

Hart, S. (2016) Allocation games with caps: from Captain Lotto to all-pay auctions. International Journal of Game Theory, 45, 37-61

Hehenkamp, B., Leininger, W., \& Possajenikov, A. (2004). Evolutionary equilibrium in Tullock contests: spite and overdissipation. European Journal of Political Economy, 20, 10451057.

Hillman, A., \& Riley, J.G., (1989). Politically contestable rents and transfers. Economics and Politics, 1, 17-40.

Holt, C.A., \& Laury, S.K. (2002). Risk aversion and incentive effects. American Economic Review, 92, 1644-1655.

Jeppesen, L.B., \& Lakhani, K.R. (2010). Marginality and problem-solving effectiveness in broadcast search. Organization Science, 21, 1016-1033.

Kaplan, T.R., \& Wettstein, D. (2006). Caps on political lobbying: Comment. American Economic Review, 96, 1351-1354.

Kawagoe, T., \& Takizawa, H. (2012). Level-k analysis of experimental centipede games. Journal of Economic Behavior and Organization, 82, 548-566. 
Kimbrough, E. O., Sheremeta, R. M., \& Shields, T. W. (2014). When parity promotes peace: Resolving conflict between asymmetric agents. Journal of Economic Behavior and Organization, 99, 96-108.

Konrad, K.A. (2009). Strategy and dynamics in contests. Oxford University Press.

Krueger, A.O. (1974). The political economy of the rent-seeking society. American Economic Review, 64, 291-303.

Laury, S.K., \& Holt, C.A. (2008). Voluntary provision of public goods: Experimental results with interior Nash Equilibria. In C. R. Plott \& V. L. Smith (Eds.), Handbook of Experimental Economics Results. (Vol. 1) 792-801. New York: Elsevier.

Lazear, E.P. \& Rosen, S. (1981). Rank-order tournaments as optimum labor contracts. Journal of Political Economy, 89, 841-864.

Lim, W., Matros, A., \& Turocy, T.L. (2014). Bounded rationality and group size in Tullock contests: Experimental evidence. Journal of Economic Behavior and Organization, 99, 155-167.

Lugovskyy, V., Puzzello, D., \& Tucker, S. (2010). An experimental investigation of overdissipation in the all pay auction. European Economic Review, 54, 974-997.

Mago, S.D., Savikhin, A.C. \& Sheremeta, R.M. (2016). Facing your opponents: Social identification and information feedback in contests. Journal of Conflict Resolution, 60, 459-481.

Mago, S.D., Sheremeta, R.M., \& Yates, A. (2013). Best-of-three contest experiments: Strategic versus psychological momentum. International Journal of Industrial Organization, 31, 287-296.

McKelvey, R.D., \& Palfrey, T.R. (1995). Quantal response equilibrium for normal form games. Games and Economic Behavior, 10, 6-38.

McKinsey \& Company. (2009). And the winner is: Capturing the power of philanthropic prizes. Retrieved from http://mckinseyonsociety.com/capturing-the-promise-of-philanthropicprizes/

Moldovanu, B., \& Sela, A. (2001). The optimal allocation of prizes in contests. American Economic Review, 91, 542-558.

Nagel, R. (1995). Unraveling in guessing games: An experimental study. American Economic Review, 85, 1313-1326.

Otsubo, H. (2013). Do campaign spending limits diminish competition? Economics Bulletin, 33, 2223-2234.

Otsubo, H. (2015). Nash equilibria in a two-person discrete all-pay auction with unfair tie-break and complete information. Economics Bulletin, 35, 2443-2454.

Rapoport, A., \& Amaldoss, W. (2000). Mixed strategies and iterative elimination of strongly dominated strategies: An experimental investigation of states of knowledge. Journal of Economic Behavior and Organization, 42, 483-521.

Rapoport, A., \& Amaldoss, W. (2004). Mixed-strategy play in single-stage first-price all-pay auctions with symmetric players. Journal of Economic Behavior and Organization 54, 585-607.

Schotter, A., \& Weigelt, K. (1992). Asymmetric tournaments, equal opportunity laws, and affirmative action: Some experimental results. Quarterly Journal of Economics, 107, 511539.

Sheremeta, R.M. (2010). Experimental comparison of multi-stage and one-stage contests. Games and Economic Behavior, 68, 731-747. 
Sheremeta, R.M. (2011). Contest design: An experimental investigation. Economic Inquiry, 49, 573-590.

Sheremeta, R.M. (2013). Overbidding and heterogeneous behavior in contest experiments. Journal of Economic Surveys, 27, 491-514.

Sheremeta, R.M. (2015). Behavioral dimensions of contests. In Congleton, R.D., Hillman, A.L., (Eds.), Companion to political economy of rent seeking, London: Edward Elgar, pp. 150164.

Sheremeta, R.M. (2016). Impulsive behavior in competition: Testing theories of overbidding in rent-seeking contests. Working Paper.

Sheremeta, R.M., \& Zhang, J. (2010). Can groups solve the problem of over-bidding in contests? Social Choice and Welfare, 35, 175-197.

Shupp, R., Sheremeta, R.M., Schmidt, D., \& Walker, J. (2013). Resource allocation contests: Experimental evidence. Journal of Economic Psychology, 39, 257-267.

Stahl, D.O., \& Wilson, P.W. (1994). Experimental evidence on players' models of other players. Journal of Economic Behavior and Organization, 25, 309-327.

Stahl, D.O., \& Wilson, P.W. (1995). On players' models of other players: Theory and experimental evidence. Games and Economic Behavior, 10, 218-254.

Szech, N. (2015). Tie-breaks and bid-caps in all-pay auctions. Games and Economic Behavior, 92, 138-149.

Terwiesch, C., \& Xu, Y. (2008). Innovation contests, open innovation, and multiagent problem solving. Management Science, 54, 1529-1543.

Tullock, G. (1967). The welfare costs of tariffs, monopolies, and theft. Western Economic Journal, 5, 224-232.

Tullock, G. (1980). Efficient rent seeking. In James M. Buchanan, Robert D. Tollison, Gordon Tullock, (Eds.), Toward a theory of the rent-seeking society. College Station, TX: Texas A\&M University Press, 97-112.

Tullock, G. (1988). Rents and rent-seeking. In C.K. Rowley, R.D. Tollison, G. Tullock (Eds.), The Political Economy of Rent-Seeking, Boston, MA, Kluwer Academic, 51-62.

Weigelt, K., Dukerich, J., \& Schotter, A. (1989). Reactions to discrimination in an incentive pay compensation scheme: A game-theoretic approach. Organizational Behavior and Human Decision Processes, 44, 26-44. 
Table 1: Overview of treatments and theoretical predictions

\begin{tabular}{|c|c|c|c|c|c|c|}
\hline Treatment & Type & $200 \quad 1 / 2$ & $29 \quad 1 / 2$ & $53 \quad 1 / 2$ & $53 \quad 1 / 6$ & 530 \\
\hline Cap $m$ & & - & 29 & 53 & 53 & 53 \\
\hline \multirow{3}{*}{$\begin{array}{l}\text { Tie-breaking rule } \alpha \\
\text { Expected bid } E(b)\end{array}$} & & $1 / 2$ & $1 / 2$ & $1 / 2$ & $1 / 6$ & 0 \\
\hline & $H$ & 30.0 & 29.0 & 30.0 & 33.3 & 23.4 \\
\hline & $L$ & 10.0 & 29.0 & 10.0 & 47.0 & 45.2 \\
\hline \multirow[t]{2}{*}{ Expected revenue $R$} & & 40.0 & 58.0 & 40.0 & 80.3 & 68.6 \\
\hline & $H$ & $\begin{array}{c}\text { Uniform } \\
\text { mixing on } \\
{[0,60]}\end{array}$ & $\begin{array}{l}\text { Atom of } 1 \\
\text { at } 29\end{array}$ & $\begin{array}{l}\text { Atom of } 0.23 \text { at } \\
53 \text {, uniform } \\
\text { mixing on }[0,46] \\
\text { with remaining } \\
\text { probability }\end{array}$ & $\begin{array}{c}\text { Atom of } 0.51 \text { at } \\
53 \text { and atom of } \\
0.03 \text { at } 0, \text { uniform } \\
\text { mixing on }[0,28] \\
\text { with remaining } \\
\text { probability }\end{array}$ & $\begin{array}{l}\text { Atom of } 0.11 \\
\text { at } 0, \text { mixing on } \\
{[0,53] \text { with }} \\
\text { remaining } \\
\text { probability }\end{array}$ \\
\hline $\begin{array}{l}\text { Bidding strategy } \\
\text { according to Nash } \\
\text { equilibrium }\end{array}$ & $L$ & $\begin{array}{l}\text { Atom of } 0.67 \\
\text { at } 0, \text { uniform } \\
\text { mixing on } \\
{[0,60] \text { with }} \\
\text { remaining } \\
\text { probability }\end{array}$ & $\begin{array}{l}\text { Atom of } 1 \\
\text { at } 29\end{array}$ & $\begin{array}{c}\text { Atom of } 0.67 \text { at } 0 \\
\text { and atom of } 0.08 \\
\text { at } 53 \text {, uniform } \\
\text { mixing on }[0,46] \\
\text { with remaining } \\
\text { probability }\end{array}$ & $\begin{array}{l}\text { Atom of } 0.85 \text { at } \\
53, \text { uniform } \\
\text { mixing on } \\
{[0,28] \text { with }} \\
\text { remaining } \\
\text { probability }\end{array}$ & $\begin{array}{c}\text { Atom of } 0.71 \\
\text { at } 53, \text { uniform } \\
\text { mixing on } \\
{[0,53] \text { with }} \\
\text { remaining } \\
\text { probability }\end{array}$ \\
\hline
\end{tabular}

Table 2: Average bid, payoff and revenue by treatment

\begin{tabular}{lcccccc}
\hline \hline Treatment & Type & $200 \_1 / 2$ & $29 \_1 / 2$ & $53 \_1 / 2$ & $53 \_1 / 6$ & $53 \_0$ \\
\hline \multirow{2}{*}{ Average bid } & $H$ & $35.2(26.5)$ & $25.3(8.7)$ & $38.6(21.1)$ & $29.3(22.8)$ & $27.0(22.9)$ \\
& $L$ & $11.7(19.3)$ & $20.2(12.8)$ & $20.5(23.9)$ & $27.9(23.5)$ & $32.3(21.8)$ \\
\cline { 2 - 7 } Average payoff & $H$ & $111.0(66.6)$ & $88.0(84.8)$ & $94.3(76.1)$ & $56.7(83.9)$ & $31.7(77.3)$ \\
Average revenue & $L$ & $-0.4(20.2)$ & $1.9(25.5)$ & $-4.8(24.3)$ & $3.3(23.7)$ & $8.0(21.7)$ \\
\hline \multirow{2}{*}{ Average bid } & $46.9(33.9)$ & $45.5(16.0)$ & $59.1(34.6)$ & $57.2(33.9)$ & $59.4(31.8)$ \\
& $H$ & $33.3(22.7)$ & $25.2(9.1)$ & $35.2(22.4)$ & $25.7(23.2)$ & $27.0(22.5)$ \\
Average payoff & $L$ & $12.4(19.8)$ & $20.2(13.0)$ & $17.5(22.9)$ & $26.1(23.9)$ & $31.2(22.2)$ \\
Average revenue & $H$ & $106.9(69.4)$ & $91.0(84.1)$ & $99.7(74.9)$ & $57.0(84.3)$ & $32.5(78.1)$ \\
\hline Styyyyyyy & $L$ & $0.8(20.6)$ & $1.0(25.6)$ & $-2.5(23.5)$ & $6.2(24.0)$ & $8.9(20.3)$ \\
\cline { 2 - 7 } & & $45.7(30.5)$ & $45.4(16.6)$ & $52.8(34.6)$ & $51.9(34.9)$ & $58.2(31.4)$ \\
\hline
\end{tabular}

Standard deviation in parenthesis. 
Table 3: Random effects GLS regression of the bid

\begin{tabular}{lccccc}
\hline \hline Variable & Coef. & St. Err. & $\mathrm{Z}$ & $\mathrm{P}>|\mathrm{z}|$ & $95 \%$ Conf. Int. \\
\hline $200 \_1 / 2 \times H$ & 23.5 & 0.99 & 23.61 & 0.000 & {$[21.54,25.44]$} \\
$29 \_1 / 2 \times H$ & 13.6 & 1.39 & 9.80 & 0.000 & {$[10.91,16.37]$} \\
$53 \_1 / 2 \times H$ & 26.9 & 2.15 & 12.50 & 0.000 & {$[22.66,31.09]$} \\
$53 \_1 / 6 \times H$ & 17.6 & 1.83 & 9.57 & 0.000 & {$[13.98,21.18]$} \\
$53 \_0 \times H$ & 15.3 & 1.60 & 9.56 & 0.000 & {$[12.20,18.48]$} \\
$29 \_1 / 2 \times L$ & 8.5 & 1.89 & 4.47 & 0.000 & {$[4.76,12.20]$} \\
$53 \_1 / 2 \times L$ & 8.8 & 2.74 & 3.22 & 0.001 & {$[3.44,14.19]$} \\
$53 \_1 / 6 \times L$ & 16.2 & 2.69 & 6.01 & 0.000 & {$[10.92,21.48]$} \\
$53 \_0 \times L$ & 20.6 & 2.12 & 9.72 & 0.000 & {$[16.46,24.78]$} \\
Constant & 11.7 & 1.25 & 9.32 & 0.000 & {$[9.26,14.20]$} \\
\hline Observations & 9600 & & & & \\
Subjects & 240 & & & & \\
Random effects GLS regression of the bid on dummies indicating the \\
interaction between a treatment and a bidder type and a constant. \\
200_1/2 C $L$ is the reference type.
\end{tabular}

Table 4: Pairwise comparisons of the weaker contestant's bids across treatments

\begin{tabular}{l|cccc}
\hline \hline & $29 \_1 / 2$ & $53 \_0$ & $53 \_1 / 6$ & $53 \_1 / 2$ \\
\hline $200 \_1 / 2$ & $<$ & $<$ & $<$ & $<$ \\
& $\mathrm{p}=0.00$ & $\mathrm{p}=0.00$ & $\mathrm{p}=0.00$ & $\mathrm{p}=0.00$ \\
$29 \_1 / 2$ & & $<$ & $<$ & $=$ \\
& & $\mathrm{p}=0.00$ & $\mathrm{p}=0.01$ & $\mathrm{p}=0.91$ \\
$53 \_0$ & & & $=$ & $>$ \\
& & & $\mathrm{p}=0.13$ & $\mathrm{p}=0.00$ \\
$53 \_1 / 6$ & & & & $>$ \\
& & & & $\mathrm{p}=0.03$ \\
\hline
\end{tabular}

The statistics in this table are based on the estimation results of the random effects GLS regression presented in Table 3. All results are robust to considering only the second half of each part.

Table 5: Pairwise comparisons of the stronger contestant's bids across treatments

\begin{tabular}{l|cccc}
\hline \hline & $29 \_1 / 2$ & $53 \_0$ & $53 \_1 / 6$ & $53 \_1 / 2$ \\
\hline $200 \_1 / 2$ & $>$ & $>$ & $>$ & $=$ \\
& $\mathrm{p}=0.00$ & $\mathrm{p}=0.00$ & $\mathrm{p}=0.01$ & $\mathrm{p}=0.16$ \\
$29 \_1 / 2$ & & $=$ & $<$ & $<$ \\
$53 \_0$ & & $\mathrm{p}=0.14$ & $\mathrm{p}=0.01$ & $\mathrm{p}=0.00$ \\
& & & $=$ & $<$ \\
$53 \_1 / 6$ & & & $\mathrm{p}=0.18$ & $\mathrm{p}=0.00$ \\
& & & & $<$ \\
& & & & $\mathrm{p}=0.00$ \\
\hline
\end{tabular}

The statistics in this table are based on the estimation results of the random effects GLS regression presented in Table 3. 
Table 6: Pairwise comparisons of the revenue across treatments

\begin{tabular}{l|cccc}
\hline \hline & $29 \_1 / 2$ & $53 \_0$ & $53 \_1 / 6$ & $53 \_1 / 2$ \\
\hline $200 \_1 / 2$ & $=$ & $<$ & $<$ & $<$ \\
& $\mathrm{p}=0.69$ & $\mathrm{p}=0.00$ & $\mathrm{p}=0.02$ & $\mathrm{p}=0.01$ \\
$29 \_1 / 2$ & & $<$ & $<$ & $<$ \\
$53 \_0$ & & $\mathrm{p}=0.00$ & $\mathrm{p}=0.00$ & $\mathrm{p}=0.00$ \\
& & & $=$ & $=$ \\
$53 \_1 / 6$ & & & $\mathrm{p}=0.59$ & $\mathrm{p}=0.95$ \\
& & & & \\
& & & & $\mathrm{p}=0.71$ \\
\hline
\end{tabular}

The statistics in this table are based on the estimation results of the random effects GLS regression presented in Table 3.

Table 7: Level-k bids by contestant type and by treatment

\begin{tabular}{lcccccccccc}
\hline \hline Treatment & \multicolumn{2}{c}{$200 \_1 / 2$} & \multicolumn{2}{c}{$29 \_1 / 2$} & \multicolumn{2}{c}{$53 \_1 / 2$} & \multicolumn{2}{c}{$53 \_1 / 6$} & \multicolumn{2}{c}{$53 \_0$} \\
& $H$ & $L$ & $H$ & $L$ & $H$ & $L$ & $H$ & $L$ & $H$ & $L$ \\
\hline Level-0 & $\mathrm{U}[0,60]$ & $\mathrm{U}[0,60]$ & $\mathrm{U}[0,29]$ & $\mathrm{U}[0,29]$ & $\mathrm{U}[0,53]$ & $\mathrm{U}[0,53]$ & $\mathrm{U}[0,53]$ & $\mathrm{U}[0,53]$ & $\mathrm{U}[0,53]$ & $\mathrm{U}[0,53]$ \\
Level-1 & 60 & Nash & 29 & 29 & 53 & 53 & 53 & 53 & 53 & 53 \\
Level-2 & $\mathrm{U}[0,60]$ & 0 & 29 & 29 & 53 & 0 & 0 & 0 & 0 & 53 \\
Level-3 & "0.1” & Nash & 29 & 29 & "0.1” & 0 & “0.1” & “0.1” & 0 & 53 \\
\hline
\end{tabular}

$\mathrm{U}[\mathrm{A}, \mathrm{B}]$ denotes a uniform distribution with boundaries $\mathrm{A}$ and B. "0.1" approximates the theoretical solution of $0+\varepsilon$ as subjects could adjust their bid to a tenth of the in-game currency. 
Figure 1: Cumulative distribution of bids versus Nash prediction by treatment and type
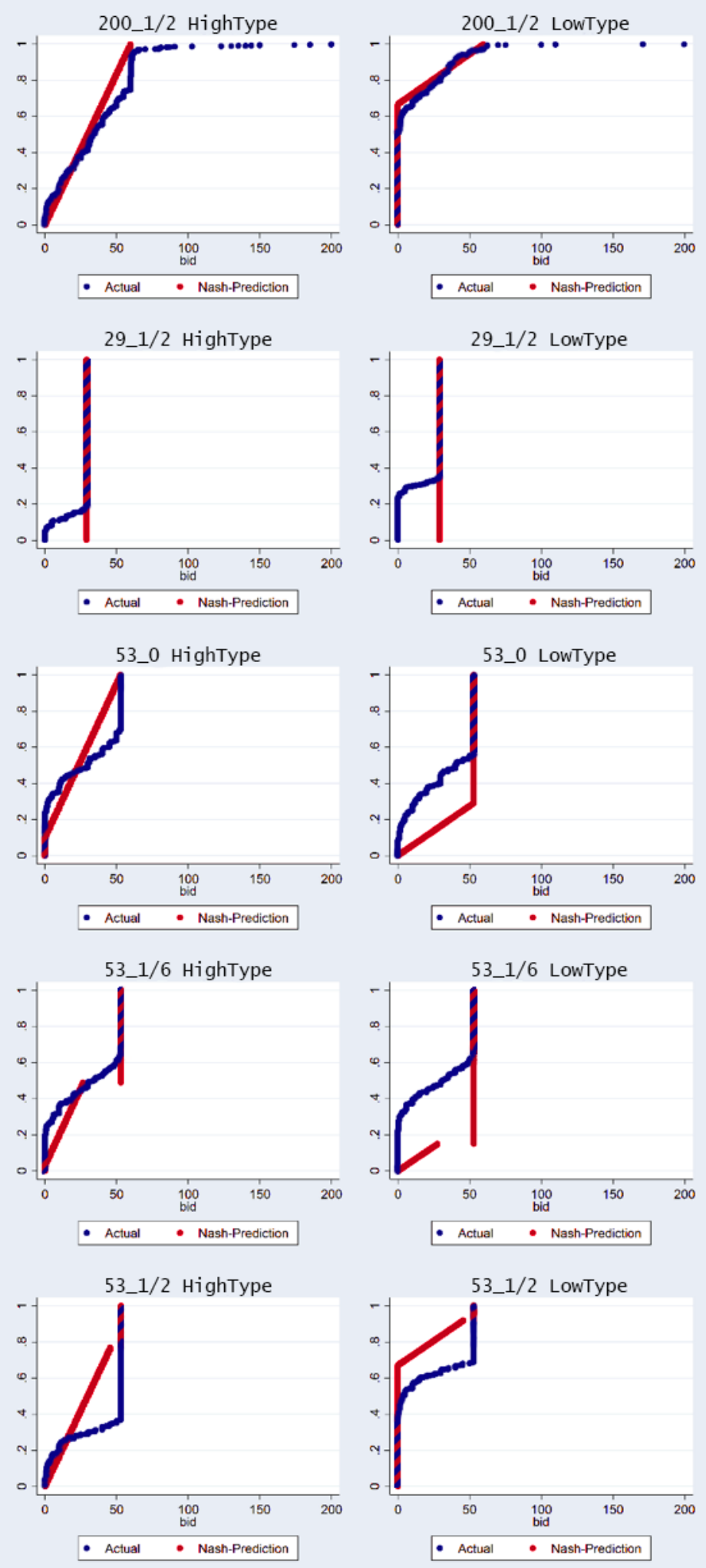


\section{Appendix (For Online Publication) - Instructions for the 53_1/6 Treatment}

\section{GENERAL INSTRUCTIONS}

Thank you for participating in this experiment. Please read these instructions carefully. If you have any questions, or need assistance of any kind, raise your hand and an experimenter will come to you and answer your questions privately. Please do not ask anything aloud. It is very important that you remain silent and do not look at other people's work. If you talk, laugh, exclaim out loud, etc., you will be asked to leave and you will not be paid. We expect and appreciate your cooperation.

During this experiment you can earn a substantial amount of money. The currency used in the experiment is Talers. Talers will be converted to euros at a rate of _60 Talers to _1_euro. The earnings from all parts will be added to a participation fee of $\mathbf{1 5}$ euros. At the end of today's experiment, you will be paid in private and in cash.

There are $\mathbf{2 4}$ participants in today's experiment. At this time we proceed to Part 1 of the experiment.

\section{INSTRUCTIONS FOR PART 1 YOUR DECISION}

The first part of the experiment consists of $\mathbf{4 0}$ decision-making periods. At the beginning of the first period, you will be randomly assigned either as participant $\mathbf{1}$ or as participant $\mathbf{2}$. You will stay in the same role assignment for the first 20 periods and then change your role assignment for the last 20 periods of the experiment. Each period you will be randomly re-paired with another participant of opposite assignment to form a two-person group. So, if you are participant 1 , each period you will be randomly re-paired with another participant 2 . If you are participant 2, each period you will be randomly re-paired with another participant 1 . You will not know the identity of the person you are matched with, and vice versa.

Each period, you may bid for a reward. The reward is worth 180 Talers to participant 1 and 60 Talers to participant 2. You may bid any number between $\mathbf{0}$ and 53 Talers (including 0.1 decimal points).

\section{YOUR EARNINGS}

After both participants make their bids, the computer will assign the reward to a participant who makes the highest bid. So, for example, if participant 1 bids 30 Talers while participant 2 bids 30.1 Talers then the computer will assign the reward to participant 2 . In case of tie, the computer will assign the reward either to participant 1 or participant 2. The chance that the computer will assign the reward to participant 1 is 1 out of 6 (16.7\% chance), while the chance that the computer will assign the reward to participant 2 is 5 out of 6 ( $83.3 \%$ chance). Therefore, in case of a tie, participant 2 is five times more likely to receive the reward than participant 1.

Remember, the reward is worth 180 Talers to participant 1 and 60 Talers to participant 2. Regardless of who receives the reward, both participants will have to pay their bids. Thus, the period earnings will be calculated in the following way:

If participant 1 receives the reward:

Participant 1's earnings $=\mathbf{1 8 0}-$ Participant 1's Bid

Participant 2's earnings $=\mathbf{0}-$ Participant 2's Bid

If participant 2 receives the reward:

Participant 1's earnings $=\mathbf{0}-$ Participant 1 's Bid

Participant 2's earnings $=\mathbf{6 0}-$ Participant 2's Bid

Remember you have already received a $\mathbf{1 5 . 0 0}$ euro participation fee (equivalent to 600 Talers). Depending on the outcome in a given period, you may receive either positive or negative earnings. At the end of the experiment we will randomly select 2 out of the first 20 periods and 2 out of the last 20 periods of the experiment for actual payment. You will sum the total earnings for these two periods and convert them to a U.S. dollar payment. If the earnings are negative, we will subtract them from your participation fee. If the earnings are positive, we will add them to your participation fee.

At the end of each period, your bid, the other participant's bid, whether you received the reward or not, and your earnings for the period are reported on the outcome screen. Once the outcome screen is displayed you should record your results for the period on your Personal Record Sheet under the appropriate heading.

\section{IMPORTANT NOTES}

At the beginning of the first period, you will be randomly assigned either as participant 1 or as participant 2. You will stay in the same role assignment for the first $\mathbf{2 0}$ periods and then change your role assignment for the last 20 periods of the experiment. Each period you will be randomly re-paired with another 
participant of opposite assignment to form a two-person group. So, if you are participant 1, each period you will be randomly re-paired with another participant 2 . If you are participant 2, each period you will be randomly re-paired with another participant 1.

Both participants will bid for a reward. The reward is worth 180 Talers to participant 1 and 60 Talers to participant 2. The computer will assign the reward to a participant who makes the highest bid. In case of tie, participant 2 is five times more likely to receive the reward than participant 1 . Regardless of who receives the reward, both participants will have to pay their bids. At the end of the experiment we will randomly select 2 out of the first 20 periods and 2 out of the last 20 periods for actual payment using a bingo cage. You will sum the total earnings for these two periods and convert them to a U.S. dollar payment.

Are there any questions?

\section{INSTRUCTIONS FOR PART 2}

\section{YOUR DECISION}

In this part of the experiment we ask you to fill out a questionnaire. Although you will not be paid for this task, we ask you to pay careful attention to each question and answer each question honestly. The answers to these questions are completely anonymous and will be used only to analyze the data.

Are there any questions? 


\section{Working Paper Series in Economics}

recent issues

No. 88 Aniol Llorente-Saguer, Roman M. Sheremeta and Nora Szech: Designing contests between heterogeneous contestants: An experimental study of tie-breaks and bid-caps in all-pay auctions, May 2016

No. 87 Johannes Karl Herrmann and Ivan Savin: Optimal policy Identification: Insights from the German electricity market, March 2016

No. 86 Andranik Tangian: Devaluation of one's labor in labor-commoditiesmoney-commodities-labor exchange as a cause of inequality growth, February 2016

No. 85 Thomas Deckers, Armin Falk, Fabian Kosse and Nora Szech: Homo moralis: Personal characteristics, institutions, and moral decision-making, February 2016

No. 84 Markus Fels: When the affordable has no value, and the valuable is unaffordable: The U.S. market for long-term care insurance and the role of Medicaid, February 2016

No. 83 Uwe Cantner, Ivan Savin, Simone Vannuccini: Replicator dynamics in value chains: Explaining some puzzles of market selection, February 2016

No. 82 Helena Barnard, Robin Cowan, Moritz Müller: On the value of foreign PhDs in the developing world: Training versus selection effects, January 2016

No. 81 Enno Mammen, Christoph Rothe, Melanie Schienle: Semiparametric estimation with generated covariates, January 2016

No. 80 Carsten Bormann, Julia Schaumburg, Melanie Schienle: Beyond dimension two: A test for higher-order tail risk, January 2016

No. 79 Frank Betz, Nikolaus Hautsch, Tuomas A. Peltonen, Melanie Schienle: Systemic risk spillovers in the European banking and sovereign network, January 2016

No. 78 Armin Falk and Nora Szech: Pleasures of skill and moral conduct, January 2016

The responsibility for the contents of the working papers rests with the author, not the Institute. Since working papers are of a preliminary nature, it may be useful to contact the author of a particular working paper about results or caveats before referring to, or quoting, a paper. Any comments on working papers should be sent directly to the author. 